\title{
Exploring Faculty and Student Frameworks for Engineering Knowledge Using an Online Card Sorting Platform
}

\author{
https://doi.org/10.3991/ijep.v10i1.11336 \\ Diana A. Chen ( $\left.{ }^{\bowtie}\right)$, Gordon D. Hoople \\ University of San Diego, California, USA \\ dianachen@sandiego.edu \\ Nico Ledwith, Eric Burlingame, Seth D. Bush, and Gregory E. Scott \\ California Polytechnic State University, California, USA
}

\begin{abstract}
In this study we investigate how faculty and students think about engineering using a technique new to engineering education: card sorting. In card sorting participants sort stimuli (cards) into groups, in the process revealing how they categorize information. Here we examine how both engineering faculty $(n=23)$ and first-year undergraduate students $(n=62)$ categorize engineering scenarios. We found engineering faculty sort based on crossdisciplinary engineering activities rather than engineering disciplines. This is a surprising result as our educational frameworks are based around disciplines, and yet they are not the primary way in which faculty think. First-year students, on the other hand, showed little consensus on how to sort the scenarios. As a part of this paper we unveil an online card sorting platform Collection and Analysis of Research Data for Sorting (CARDS). CARDS allows researchers to create card sorting tasks, distribute them to participants for remote data collection, and analyze quantitative results.
\end{abstract}

Keywords - Faculty attitudes; interdisciplinary; assessment tools; student perception; philosophy of engineering education

\section{Introduction}

As engineering educators, we aspire to train our students to 'think like engineers' an often used but ill-defined term [1]. What, exactly, does it mean to be an engineer? The earliest use of the word engineering can be traced back to the 14th century where it described an individual who designed and built military engines [2]. While many engineers still work on military applications today, the field of engineering has expanded tremendously: there are now over 619,000 full-time engineering students enrolled in more than 950 unique degree granting programs [3]. As a part of this growth, engineering has become increasingly specialized, allowing many different disciplinary areas to emerge, each with its own unique engineering identity [4], [5]. These identities are solidified in traditional engineering curricula: mechanical engi- 
neers learn about power cycles and civil engineers learn about concrete. While this is changing, many programs still emphasize these traditional disciplinary divides.

In this pilot study, our first objective was to examine if these disciplinary silos impact the way in which engineering faculty think about engineering. We developed a set of stimuli - short written descriptions of engineering scenarios - and asked faculty across a variety of institutions to group them into categories. We suspected that faculty might sort scenarios in one of two ways: either using engineering disciplines or a set of cross-disciplinary activities. Our second objective was more exploratory: we administered the same survey to first-year students across a variety of majors (engineering and non-engineering) at our primarily undergraduate, private four-year institution. We suspected that students' sorts would not map nicely onto our proposed frameworks, as the study was conducted in the first week of the semester before exposure to engineering content. Moreover, we suspected the student sorts might reveal emergent frameworks with properties similar to K-12 studies on conceptualizations of engineering knowledge (e.g., the Draw an Engineer Test (described below) extracts themes of students' perceptions of what an engineer looks like and does).

The approach we used is known as card sorting, where participants are asked to sort a series of cards (in this study, the engineering scenarios) using any fundamental organization scheme they feel is appropriate. For example, cards containing pictures of cars could be sorted by color, size, or number of doors, with no 'correct' way to sort. This technique is often used in the user-experience (UX) design of web interfaces, where users are asked to sort cards into categories to provide usability feedback on, for example, how to organize context menus [6] - [8]. Additional sources also describe the process of designing and implementing a card sort for a generalized audience [9]. Within academic settings, this method has been used in a variety of research applications: cognitive psychologists have used it to measure expertise in a variety of disciplines [10], and anthropologists refer to it as 'pile sorting' and use it in cultural domain analysis [11]. Most germane to this study, card sorting has been used by education researchers to measure conceptual expertise in physics [10], biology [12] [13], and chemistry [14] [15]. These studies showed card sorting to be a useful tool in distinguishing students from faculty. In particular, Krieter et al. (2016) showed card sorting can be used to track the progress of students towards more expert-like thinking. Our study, the first of our knowledge to use card sorting within engineering education, focuses primarily on probing what frameworks engineering faculty and a variety of undergraduate majors use to conceptually organize engineering knowledge. We operationalized our research with three research questions:

- To what extent do faculty use an engineering discipline-based framework, crossdisciplinary activity-based framework, or neither, when sorting engineering scenarios?

- To what extent do first-year students use an engineering discipline-based framework, cross-disciplinary activity-based framework, or neither, when sorting engineering scenarios?

- How do students' conceptual organization of engineering scenarios compare to that of faculty? 
In addition to investigating these research questions, in this paper we also describe an online card sorting tool we have developed - Collection and Analysis of Research Data for Sorting (CARDS). This platform is a major step forward in card sorting research, making it possible to collect high-fidelity data remotely without use of a facilitator. CARDS removes the need to print physical cards, perform data entry by hand, and meet participants in person. While traditional qualitative studies often necessitate smaller sample sizes due to their intensive methods, CARDS enables researchers to easily administer and analyze card-sorting activities with larger populations. While some online card sort tools exist (such as Roistr [16] and Proven by Users [17]), CARDS is designed specifically for educational research applications.

\section{Background}

The research presented here engages in a conversation with two existing bodies of literature. The first focuses on how to measure expertise, while the second explores how different populations (namely students and engineering faculty) conceptualize engineering. In keeping with vom Brocke et al.'s call for disclosure on the literature review process [18], we focused on drawing from scholarship by leaders in engineering education. Our process began with a broad introductory search on Google Scholar using keywords of our study. Our resulting references do, however, reveal an American bias in our study, as we primarily focused on sources such as the Journal of Engineering Education and the conference proceedings from the American Society of Engineering Education Annual Conference and Exposition.

\subsection{How is knowledge or expertise measured?}

The development of expertise has been studied in a wide range of fields, and educators have long looked to experts in the field to define the goals for student graduates [19], [20]. Previous research suggests that experts organize knowledge based on a deep understanding of concepts, whereas novices (e.g., students) often use superficial connections (such as literal features) to organize knowledge around fundamental concepts [8], [10]. The differences between how experts and novices organize knowledge can reveal the depth of understanding of a domain [18, p. 49]. In other words, conceptual organization can point to the depth of conceptual knowledge. Often, an expert's knowledge is used as the reference point for evaluating the development of expertise.

Two commonly known tools used in education to probe expertise are concept maps and concept inventories. Concept maps can be used to visualize integration of knowledge by drawing connections between related topics [22], [23]. Many software tools now exist to aid in concept mapping [24]. While concept maps can be very useful in mapping knowledge, their open-endedness can make assessment ambiguous, as gaps, inappropriate links, and misconceptions become a challenge to identify [21]. Concept inventories, on the other hand, are created by experts to specifically identify misconceptions and assess accurate knowledge in novices. Typically used as diagnostic and/or summative assessments of students' understanding of fundamental con- 
cepts, its scope is limited to topic areas covered within a single course or course sequence. Concept inventory exams usually involve multiple-choice problems specifically designed with misleading solutions that reveal common misconceptions [25]. While concept inventories are effective in investigating misconceptions, they are close-ended by only allowing for one correct answer.

While concept maps and concept inventories can be powerful, the approach taken in this study (card sorting) allows us to probe how both experts and novices organize conceptual knowledge -- a distinctly different question from studies that examine how expertise is developed [8] or misconceptions of engineering [25]. Our card sorting approach situates our study between open-ended concept maps (where evaluation against an expected outcome is difficult) and close-ended concept inventories (where there is one correct answer - the expert's answer). As this is the first study to our knowledge that uses card sorting in engineering education, we have provided a detailed primer on how to conduct card sorting research using in the supplementary information for this paper for readers unfamiliar with this approach.

\subsection{How can we measure engineering expertise?}

While other card sort studies have measured the development of disciplinary expertise, we chose to focus on the similarities of conceptual knowledge between various engineering disciplines. Engineering encompasses a wide variety of different types of programs - a bioengineering program that practices gene editing is very different from a civil engineering program that analyzes steel and concrete building materials. As such, it is difficult to broadly define who an 'engineering expert' might be. In fact, recent legal controversies have surfaced around this specific question: is an engineer simply a matter of someone with educational degrees, or is it based on licensure and practice [26] [27]? We recognize that most engineering faculty are not practicing engineers, and what is considered 'engineering expertise' in academia may not align with what is considered expertise in industry. As such, our study only treats engineering faculty as 'putative experts' relative to the students. Our goal is not to define what faculty consider to 'qualify as engineering' or to extract what 'engineering expertise' is, but to explore if engineering faculty tend to conceptualize engineering as separated by disciplines or see engineering as a set of cross-disciplinary activities. We then compare this with how students conceptualize engineering in an effort to draw meaningful conclusions about the differences between novice perceptions of engineering and those of educators.

\subsection{What do engineering faculty think engineering is?}

There are a variety of studies in engineering education that investigate how engineering faculty conceptualize engineering. Godfrey \& Parker (2010) conducted a study that sought to guide our engineering culture by answering 'where are we' and 'how to get to where we want to go.' Their findings divide 'an engineering way of thinking' into five themes: the role of mathematics as the tool and language of engineering, the prevalence of visual communication, problem solving and design, the 
acceptance that there are 'best' but not always 'right' answers, and the underpinning assumption that engineering laws and processes are race- and gender-free [28]. In addition, Pawley (2009) conducted a qualitative study on engineering faculty from various disciplines to examine how they explicitly or implicitly describe the boundaries of their discipline [29]. The three big themes that emerged from the interviews centered around engineering as applied science and math, engineering as problemsolving, and engineering as making things. Interestingly, the themes found in both of these studies suggest that engineering faculty do not see engineering as based on discipline, but rather as tools, assumptions, and activities that span engineering disciplinary silos.

\subsection{What do novices think engineering is?}

For novices, who by definition have less knowledge than experts, we instead examined literature on their perception of engineering. Many of these perception studies use the Draw an Engineer Test (DAET) [30]-[36], which asks students primarily in elementary and secondary school to draw their perception of what an engineer looks like and does. The DAET is a qualitative measurement tool that involves coding the artifacts and features found in students' drawings of engineers, such as skin color and gender, and whether the engineer is human or non-human. The activities found in the drawing are also documented. The top activities across four different studies included terms such as builds, fixes, creates, designs, and invents, among a few others [31][34]. Capobianco et al. (2011) summarize their results from grades 1-5 into four categories: An engineer is:

- A mechanic who fixes engines or drives cars and trucks

- A laborer who fixes, builds, or makes buildings, roads and other structures

- A technician who fixes electronics and computers

- Someone who designs.

While the first three are simple conceptions of what an engineer does, namely a fixer (divided into mechanical, electrical, and civil fields), the fourth is unique in its abstract nature. The authors further explain that an engineer as a designer arose only among older students (4th-5th grade), and only $17 \%$ of the time [30]. As it is still uncommon for engineering to be a part of the K-12 curriculum in the United States [37], we treat the first-year undergraduate students in our study as novices who have not encountered significant engineering content previously, and we hypothesize that their card sorts may reveal similar properties found in these K-12 engineering perception studies.

While concept maps and concept inventories are frequently used as educational tools to measure expertise, our study uses card sorting as an open-ended way to measure how students and engineering faculty organize engineering knowledge. In particular, the flexible yet measurable results of a card sort lend this tool to be fitting for exploring knowledge of engineering, as the field has become more and more specialized throughout history. While two frameworks are hypothesized as starting points in 
a card sort, these frameworks are not revealed to participants in our study, allowing them to use any framework that reveals their own organization of knowledge. The existing literature on measuring perceptions and conceptualizations of engineering provide a basis for the results we might expect for our research questions.

\section{Methods}

In this pilot study, we use card sorting as an open-ended tool to explore how engineering faculty across institutions and first-year undergraduate students in a variety of majors at a single institution conceptualize engineering by examining the ways in which they organize a set of engineering scenarios. In particular, we also sourced engineering faculty from a variety different disciplines to see if a common framework would emerge from the card sort regardless of disciplinary identity. Based on the cards provided to them, we investigated if engineering faculty from various disciplines would tend towards a consensus of some organizational framework to sort cards within. We hypothesized that faculty would sort the cards according to one of our two proposed frameworks (engineering disciplines or cross-disciplinary engineering activities), and that given the same cards, first-year students' sorts would not align neatly with either of our frameworks but might reveal common perceptions of engineering.

\subsection{Development of an online card sorting tool (CARDS)}

Previous card sorting studies in education research [12] - [14] have required participants to sort physical cards and fill out survey forms by hand, with in-person facilitators to conduct the study. Performing card sorting research in this manner brings with it a litany of logistical challenges: participants must be physically present, large numbers of paper cards must be kept organized, it is hard to dynamically enforce sorting rules, and the data must be entered manually from paper surveys (especially challenging when handwriting is hard to read). Furthermore, once the data is converted to a digital format, researchers must write data analysis scripts to compute various card sorting metrics - a non-trivial task. We recognized these barriers to doing card sorting research and designed an online platform, CARDS, to simplify both data collection and analysis and alleviate issues associated with paper-based implementation. An overview of our approach for card sorting using CARDS is shown in Fig. 1. 


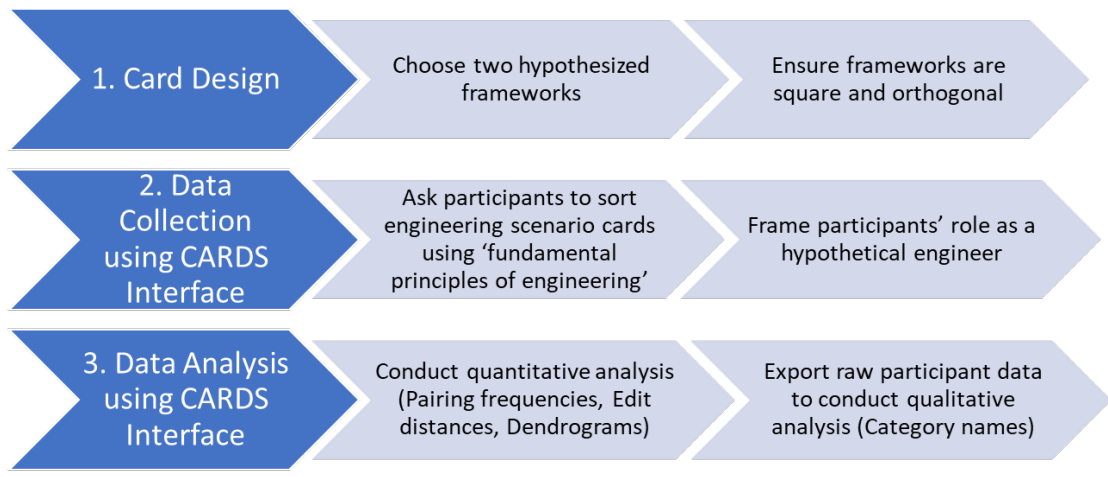

Fig. 1. Diagram of overall study method.

CARDS is a fully integrated approach that allows researchers to create card sorting tasks, distribute them to participants, collect the data, and analyze the results (see interface example in Fig. 2). CARDS can be used to perform both unframed and framed sorts depending on how the tool is configured (see supplementary information for more about these different sort types). Researchers or education practitioners interested in using CARDS may contact author Gregory Scott (gscott02@,calpoly.edu) for access or visit https://atom.calpoly.edu/cardsort/login.

Fig. 2 shows the CARDS interface with an example sort in progress. Cards begin stacked in the upper left box and unsorted cards can be read in any order by using the card shuffle feature. CARDS features a drag-and-drop interface that allows for a flexible and modular workflow for participants to think while they sort. We designed this interface to encourage users to place cards anywhere on the screen as they sort, replicating the physical act of creating and reshuffling groups that we have observed participants do with non-digital card sorting. Boxes are highlighted when a card is detected within its boundaries, and a status bar in the upper right indicates if users are violating any of the sorting rules prescribed by the researchers. Note that the text in Fig. 2 is intentionally nonsensical to direct readers away from the placeholder text and towards the mechanics of the new online interface.

A major benefit of the digital approach is that it allows the researcher to strictly enforce activity parameters (e.g., participants must use at least two categories). In addition to card sorting, CARDS can also be used to collect informed consent and survey data (such as demographic information) from participants. Overall, CARDS makes it possible to perform remote data collection on card sorting tasks with a high fidelity of implementation without the need for direct oversight. 


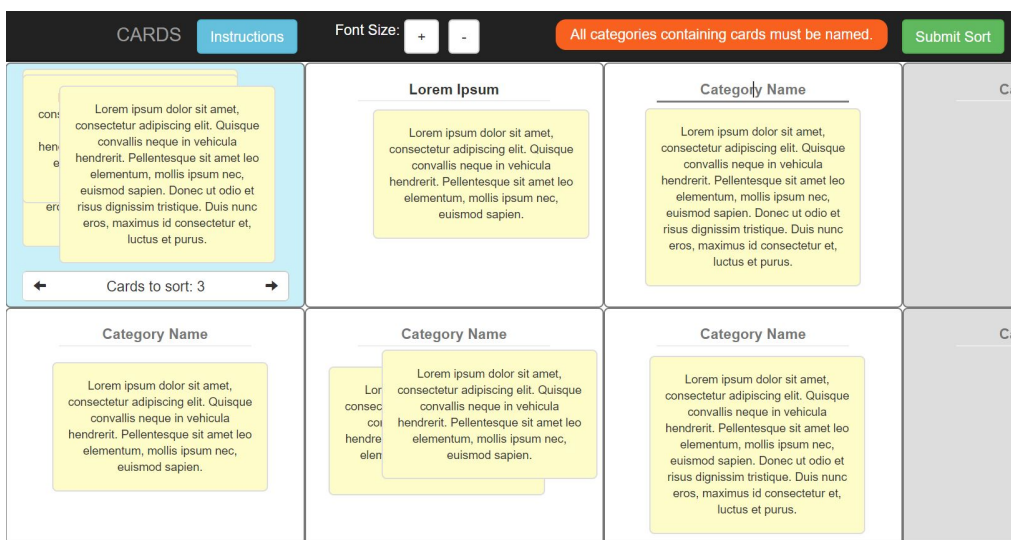

Fig. 2. CARDS Interface displaying example sort (using nonsensical placeholder text).

\subsection{Card design}

One of the most challenging aspects of card sorting research is designing the cards. We selected our two frameworks from our observations of engineering: Disciplinary silos are well established in engineering academe, but engineering practice is often organized around functional teams tasked with a particular activity (such as design or analysis groups found in industry). Our 'engineering disciplines' framework included four major disciplines that were very distinct: mechanical, electrical, civil, and bioengineering. Our 'engineering activities' framework was organized around common groupings used by industry: design, testing, analysis, and communication. To enable the sort analysis, these two frameworks must be orthogonal. For example, the full text of one of our cards is shown below:

A suspension bridge has displayed indication of recent freeze-thaw damage. You drive to the bridge and collect data on the bridge cables' behavioral response.

This engineering scenario could be categorized as civil engineering in the discipline framework and as testing in the activity framework. It is important to note that card sorting uses these proposed frameworks as a starting point for analysis but does not preclude participants from using other frameworks in their sorts. The cards act as stimuli that can be sorted in any way that fits the participant's fundamental organizational schema. The specifics of all the cards in our study are not shared here to maintain the integrity of future studies but can be provided upon request.

\subsection{Data collection}

We administered our card sorting survey to two different groups: engineering faculty from a wide range of institutions and disciplines, and first-semester college students at a primarily undergraduate, private four-year institution. To ensure diversity from multiple engineering disciplines for our faculty group, we targeted both faculty at our own institution (14 engineering faculty at the University of San Diego), as well as 33 faculty from a variety of institutions who attended a small, interdisciplinary 
engineering conference. Our faculty population $(n=23)$ resulted from a total of 47 requests sent with a response rate of $49 \%$. Each email was individually addressed to encourage participation. We targeted two first-year student populations: 252 nonengineering students randomly chosen from the entering class ( 26 responses) and all 160 students enrolled in our introduction to engineering course (36 responses). Our student population $(n=62)$ resulted from 412 email invitations with a response rate of $15 \%$. These response rates were similar to what is typically reported in literature for survey-based research: internal surveys (such as ours personally directed towards faculty) typically receive a $30-40 \%$ response rate, and external surveys (such as the mass email to first-year students) typically receive a $10-15 \%$ response rate [38], [39]. To avoid introducing any bias from what students learned in their introductory engineering course, we sent the survey during orientation weekend before the start of the semester. In addition to emailing the students, we made announcements during both orientation and the first day of class to raise awareness of the study. The survey window was closed after the first day of class. Both faculty and student groups were incentivized with a raffle for a $\$ 100$ gift card. In this approximately 10 minute activity through the online CARDS platform, participants were asked to sort the cards into categories that they believed were 'fundamental principles of engineering' (emphasis on wording in instructions [40]). From initial tests, we discovered the importance of framing the participant's role as a hypothetical engineer in order to elicit thoughtful responses (particularly from students).

\subsection{Data analysis}

Card sorting provides a rich wealth of both qualitative and quantitative data that can be analyzed in a range of different ways. We used the built-in suite of analysis tools of our CARDS platform to perform the calculations used for our quantitative analysis. The tool automatically calculates some useful quantitative card sorting metrics which allow the researcher to evaluate how closely an individual's sort compares to the hypothesized sorts (i.e., complete match with the proposed framework). While detailed explanations of each of these parameters are provided in Krieter et al. [14], brief descriptions are included below:

- Edit distance is the minimum number of card moves required to achieve a perfect hypothesized sort

- Percent pairings is the percent of card pairings in an individual's sort that is common with possible pairings in the hypothesized sort

- Pairing frequency matrices show how often a group of participants paired particular cards together

- Comparison-based indices compare the sorts between two populations without need for a hypothesized reference.

In keeping with previous studies [12]-[14], we opted to use the student's t-test to compare population means. However, these metrics can be compared using any traditional statistical measure. 
Using CARDS, we also exported the raw participant data for qualitative analysis in Excel. As an online platform, CARDS provides a variety of ways to visualize the various features contained in the raw data. For example, participant sort data can be aggregated by the multitude of category names that participants attributed to a certain card, or the combinations of cards that were given a certain category name, all itemized by individual participants. The former is useful for determining if there was group name agreement across participants for a single card, while the latter is useful for identifying unexpected card groupings that suggest emergent frameworks. CARDS also facilitates analysis of demographic information and its correlation to sort data, if differences between participants are of interest.

With itemized participant data, we were able to examine our data in two ways. First, we applied a systematic coding to the category names assigned by participants to determine whether they matched any of our eight hypothesized category names. Several iterations were required, with discussion and adaptations to our coding rubric, before we reached a $100 \%$ interrater reliability between two raters (authors DC and $\mathrm{GH})$. Second, as a complement to evaluating if the sort data aligned with our frameworks, we created stem plots from the raw data using the same coding rubrics as before to identify any potential emergent frameworks that were common between many participants.

\section{$4 \quad$ Results}

The results to our research questions can be summarized using three quantitative metrics, with additional discussion about our qualitative findings. Fig. 3 shows the pairing frequencies and edit distances of both faculty and student groups in relation to both hypothesized frameworks. Both of these metrics are visualized as box-andwhisker plots, where the box encompasses the median of the first quartile to the median of the third quartile of data, the solid line represents the median of the full dataset, the whiskers extend to the minimum and maximum values in the set after removing outliers, and open circles represent outliers.

A low pairing frequency indicates that participants grouped very few hypothesized card pairs in a given framework. For example, the median faculty sort had only $13 \%$ pairs that matched the discipline framework (Fig. 3, left), suggesting that faculty did not tend to sort based on engineering disciplines. Edit distances refer to the minimum number of cards needed to be moved to match a hypothesized sort, and so high edit distances suggest little overlap with that framework. For example, the high values of edit distance for faculty in the discipline framework indicate that many cards needed to be moved to attain a perfect discipline-based sort. Statistical comparisons are provided in Tables 1 and 2 . 

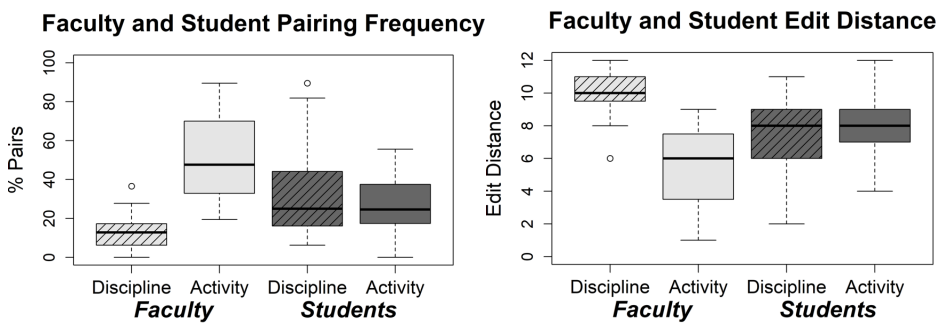

Fig. 3. Box-and-whisker plots for pairing frequency (left) and edit distances (right) of faculty and student sorts. Results of both participant groups are shown with respect to both the discipline-based framework (striped) and the activity-based framework (solid).

Table 1. Descriptive statistics for faculty and student pairing frequency.

\begin{tabular}{|c|c|c|c|c|c|c|c|}
\hline & \multirow[b]{2}{*}{$N$} & \multicolumn{2}{|c|}{ Discipline Framework } & \multicolumn{2}{|c|}{ Activity Framework } & \multirow[b]{2}{*}{ t-value } & \multirow[b]{2}{*}{ P-value } \\
\hline & & Mean & $S E$ & Mean & $S E$ & & \\
\hline Faculty & 23 & $13 \%$ & $1.9 \%$ & $52 \%$ & $4.9 \%$ & -7.390 & $<0.001$ \\
\hline Students & 62 & $33 \%$ & $2.7 \%$ & $27 \%$ & $1.8 \%$ & 1.795 & 0.07 \\
\hline t-value & & -5.832 & & 4.853 & & & \\
\hline P-Value & & $<0.001$ & & $<0.001$ & & & \\
\hline
\end{tabular}

Table 2. Descriptive statistics for faculty and student edit distances.

\begin{tabular}{|c|c|c|c|c|c|c|c|}
\hline & \multirow[b]{2}{*}{$N$} & \multicolumn{2}{|c|}{ Discipline Framework } & \multicolumn{2}{|c|}{ Activity Framework } & \multirow[b]{2}{*}{ t-value } & \multirow[b]{2}{*}{$P$-value } \\
\hline & & Mean & $S E$ & Mean & $S E$ & & \\
\hline Faculty & 23 & 10.1 & 0.31 & 5.5 & 0.52 & 7.530 & $<0.001$ \\
\hline Students & 62 & 7.6 & 0.30 & 8.1 & 0.24 & -1.268 & 0.21 \\
\hline t-value & & 5.633 & & -4.577 & & & \\
\hline P-Value & & $<0.001$ & & $<0.001$ & & & \\
\hline
\end{tabular}

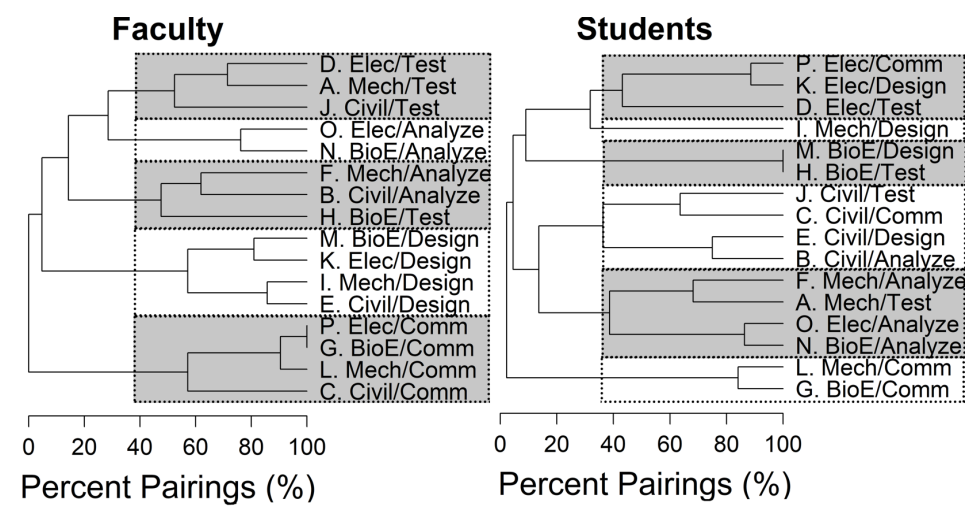

Fig. 4. Hierarchical clustering as represented by a dendrogram for faculty sorts (left) and students' sorts (right). Faculty dendrogram branches tended to align with our engineering activity framework, while students had less consensus in their data. 
Using the pairing frequency matrix generated by CARDS, we also performed a hierarchical clustering in $\mathrm{R}$ using the ward.D algorithm and created dendrograms for each participant group. Dendrograms are tree diagrams used to visualize the relationship between similar sets of data, and in this case, illustrate how participants tended to group certain cards. Fig. 4 illustrates the clustering of the faculty sorts and student sorts by setting a cut-off threshold of 1 in a scree plot analysis. While the faculty dendrogram has five main branches (each boxed in the figure), the six branches in the student data suggest more disagreement of card pairs between students.
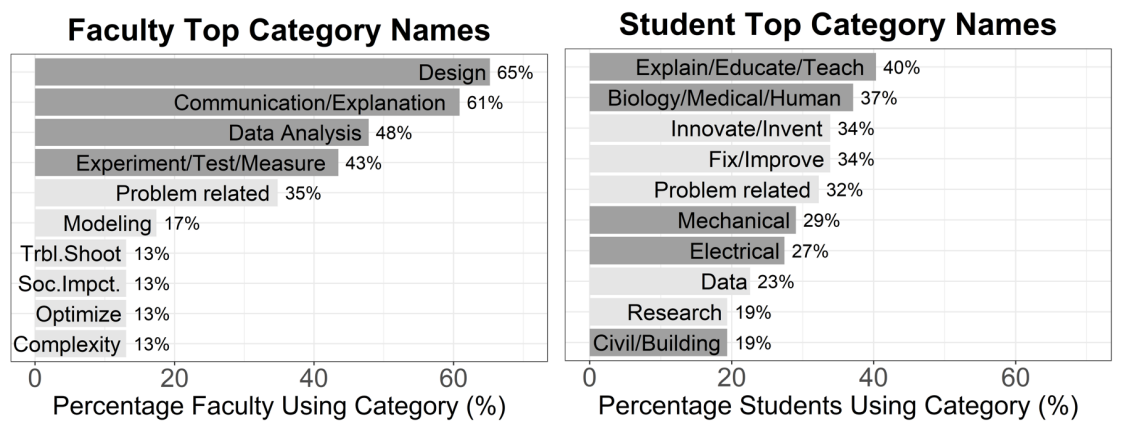

Fig. 5. Top 10 category names used by faculty $(n=23$, left $)$ and by students ( $n=62$, right) based on qualitative analyses of sort data. Values shown indicate the percentage of each participant group that used each code, and darker grey bars indicate a match with hypothesized group names. The top four names used by faculty match our activity features, while the discipline features (and communicate) can be found in the top student category names.

We also examined our qualitative data to determine what participants named their groups when they did not align with our hypothesized frameworks. Fig. 5 shows the top 10 card group names used by our participants. Some group names used were similar to those in our hypothesized frameworks; however, qualitative analysis revealed that these groups often consisted of unpredicted card pairings.

\section{Discussion}

\subsection{Findings on RQ1: engineering faculty tended towards cross-disciplinary activities over disciplines}

We found that faculty did not use disciplinary frameworks when categorizing engineering scenarios. In our quantitative data, the lack of disciplinary sorting can be observed in both the pairing frequency and edit distances (Fig. 3). The pairing frequency for faculty using discipline-based group names was low but not zero, indicating that a few faculty responses included card pairs expected in a discipline-based sort. This is actually a misleading indicator, as upon reviewing the qualitative data, none of our faculty participants used any type of discipline as a category name. From 
the raw sort data, we can trace two reasons that faculty paired cards from the same discipline. First, several faculty collapsed the activity categories of test and analyze, resulting in groups that contained test and analyze cards from the same discipline. (Examining our cards after seeing these results, we realized our card descriptions were not as clearly delineated as they could have been. For example, one analyze card unambiguously had the word test in its text.) Second, some faculty used alternative frameworks that resulted in cards from the same discipline being paired. For example, one faculty member used a group named 'high human impact' that contained three cards related to civil engineering. Faculty edit distances illustrate the same trend: that faculty sorts shared few card pairings with the hypothesized discipline-based framework. Overall, we can confidently conclude faculty did not use the discipline framework when sorting engineering scenarios.

The hierarchical clustering analysis of faculty data, shown as a dendrogram in Fig. 4 , corroborates our finding by illustrating how faculty tended towards sorting based on engineering activities rather than disciplines. The five branches align closely, but not exactly, with those in our hypothesized activity framework. Four cards neatly arrange into design and communication groups; however, the test and analyze cards are not quite as cleanly sorted. As mentioned above, there was some confusion about our test and analyze cards, resulting in three clusters instead of two - one for test, one for analyze, and one group that contained both types.

While the top four branches in the faculty dendrogram matched the four categories in the activity-based framework, there was still a range of group names used by faculty found in the qualitative data that was unrelated to either framework. Fig. 5 shows the top 10 category names used, as well as the percent of participants that used that group name. These data support the conclusion that faculty clearly tended away from the discipline framework as there were no disciplinary names used. Rather, faculty gravitated towards the four activity-based categories we hypothesized (70\% used at least two, and 57\% used at least three in their group names) further confirming that this is one prevalent way that engineers think about the world.

\subsection{Findings on RQ2: first-year students did not clearly use either hypothesized framework}

We presumed that first-year students would sort the cards differently than faculty, but we were unsure of the framework they would use. While all four discipline-based features appeared in the students' top ten category names, we found that students did not predominantly use either of our hypothesized frameworks. With 16 cards, students' sorts had an edit distance of 8 for both the discipline and activity frameworks, indicating no tendency towards either framework (Fig. 3). This lack of consensus is also illustrated in Fig. 3, which shows the results from hierarchical clustering for student sorts. These data show that students did use some parts of the disciplinary framework-for example, civil engineering and electrical engineering groupings are evident. Other groupings, however, show no consistent trend. (It is important to note that while one of the emergent groups from the hierarchical clustering appears to focus around test and analyze cards, the qualitative data in Fig. 5 suggest the students 
were not grouping these cards with test or analyze in mind, as neither of these terms appear in the top category names. Instead, the pairings of these cards were primarily designated as problem- or solution-related.)

Interestingly, as shown in Fig. 5, the top category used ('explain/educate/teach') was related to our communicate group in the activity framework, while the second ('bio/medical/human') was related to our bioengineering group in the discipline framework. As students did not closely align with either framework, we also coded the qualitative data for emergent frameworks. The next three top categories fell outside of either hypothesized framework: students saw engineers as innovators/inventors, people who improve or fix devices, and categorized scenarios as 'problems' to be defined or solved. These perceptions matched those commonly identified in literature for primary and secondary school students, as described above in the results of multiple Draw an Engineer Tests [31]-[34]. While our study was conducted prior to any substantial engineering knowledge being covered in the college classroom, the lack of change in perception of engineering, despite students reaching college, is surprising.

This led us to wonder if the data were influenced by the first-year students' plans to major in engineering or another discipline. We investigated this by further dividing the student group into first-year non-engineering students $(n=26)$ and first-year engineering students $(n=36)$, determined from students' self-identification in demographic data. Our analysis shows that the engineering students were not significantly different from their peers in how they sorted engineering scenarios. The similarity of the two student groups is present in every card sorting metric we examined; a representative plot (percent pairs for the disciplinary framework) is shown in Fig. 6. We computed unequal variance t-tests on four measures between the two groups of students (edit distances and percent pairings to both the disciplinary and activity-based frameworks.) In all cases, we found no statistical differences between group means (all $p$ values $\cong 0.4$ ).

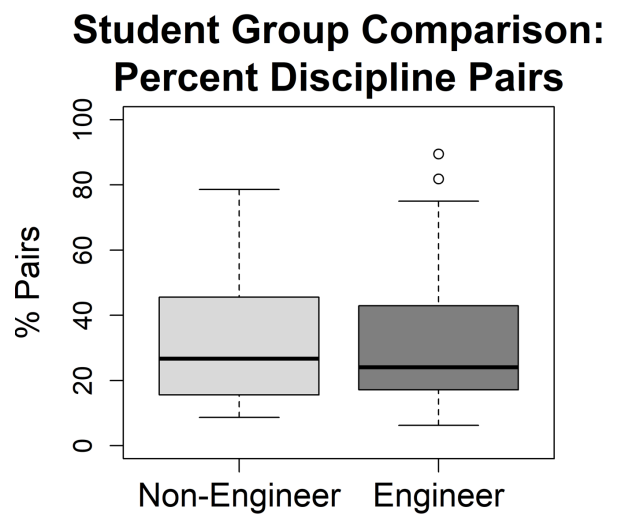

Fig. 6. Representative chart illustrating first-year engineering and non-engineering students' data are similar (\% pairing for discipline framework shown here). In all quantitative metrics, no statistical difference was found between these groups ( $\mathrm{p}$-values $\cong 0.4$ ). 


\subsection{Findings on RQ3: comparisons between faculty and students}

As we might expect from individuals with similar areas of expertise, the faculty demonstrated a stronger group consensus on their preferred framework than students did. This can be observed in Fig. 5 by examining the top category names used by each group: after the top five faculty categories, there is a sharp decline in the relative frequency of category names. The student data, on the other hand, shows a much more gradual decrease in the frequency of group names - this reflects less coherence of viewpoints in the student group than in the faculty group.

Additionally, unequal variance $t$-tests on four measures (edit distances and percent pairings to both the hypothesized disciplinary and activity-based frameworks) also revealed statistically significant differences between the two groups. As with previous studies [14], our data showed some moderate skewness. As the $t$-test is robust to such skewed data and we had a high degree of significance between groups (all $p$-values $<$ 0.001 ), it is unlikely that the results would be impacted by this skewness.

Faculty and students did, however, overlap in two of the ways they sorted the cards. The fifth most popular category name for both groups was problem-related, which was an aggregation of category names that included problem definition, problem identification, a problem to be solved, problem-solving, or simply 'problem.' This was an emergent category that could have easily been the basis for an entirely separate hypothesized framework, as novices in the Draw an Engineer Tests as well as engineering faculty from Pawley's work both used concepts of maker, fixer, or problem-solving to define an engineer. The other area of overlap was between the faculty group 'communicate' and the student group 'explain/educate/teach.' While both groups included many synonyms of the term 'explain', faculty group names included more 'communicate' and 'reporting' terms, while students' use of terminology was less technical, such as 'teaching' or 'sharing knowledge.' Because the 'communicate' cards were noticeably different from the other engineering scenarios, the selection of our hypothesized categories may have caused more overlap between students and faculty than we expected.

\subsection{Study limitations}

There are two major limitations to this pilot study that should be considered when evaluating the results. First, the faculty and student populations are relatively small $(n=23$ and $n=62$, respectively). While the faculty population included diverse engineering disciplinary areas, roughly half of the faculty respondents in the study reside at one institution, and all reside in the United States. Similarly, while the student population represented a diverse disciplinary group, all of the students were surveyed from a single U.S. institution (private four-year college, with a wealthy and majority White population). While we suspect that this single institution bias is not a major factor (at least in relation to other U.S. institutions), international studies may reveal different trends.

A second limitation of this study is our narrow focus on two groups: first-year students and faculty. We chose these two groups as populations at opposite ends of the 
academic spectrum in the formation of an engineering mindset (faculty teach this, while engineering students are learning this). In future studies, it would be interesting to use card sorting to examine the ways in which engineering student thinking evolves over time. For example, Krieter et al. used card sorting to track students' development of expertise throughout a four year chemistry program [14]. We think a similar study would be interesting within engineering.

\section{Conclusion}

In this pilot study, we examine the ways in which engineering faculty and students categorize engineering scenarios using an online card sorting platform we developed. We found that engineering faculty tended to think about engineering not in disciplinary terms, but as an endeavor that cuts across disciplinary boundaries. First-year students had less agreement in what frameworks they used to categorize engineering scenarios, which included emergent categories that shed light on their view of engineers as innovators, fixers, and problem-solvers. These results align with what others have found in non-card sorting studies with engineering faculty and K-12 students. Some limitations of this pilot study include over-representation of participants from our institution in the faculty population, and a rather uniform student body. While our results are not unexpected, we also provide readers with an in-depth look at how to design, build, and analyze card sorting tasks using our newly developed CARDS platform.

Anecdotal evidence from both faculty and students have suggested to the authors that many students entering college may not have a good grasp on what engineering is, even though they choose it as their major. Our study adds to the growing body of literature highlighting the need for engineering education at younger ages to better prepare students for college. Future work could utilize CARDS to conduct a longitudinal study of engineering students to examine whether the transition from perceptions of engineering to interdisciplinary engineering activities occurs in the college curriculum, in graduate school, or outside of academia entirely.

\section{$7 \quad$ Acknowledgement}

We are grateful to Dr. Kimberly Tanner (SFSU) for her inspiration, support, and fruitful conversations in developing our study. Thanks also to Dr. Joel Alejandro Mejia (USD) for guiding us through both the engineering education literature and the research design process. This work was supported through the Bill and Linda Frost Fund at Cal Poly San Luis Obispo as well as University of San Diego faculty startup research funds. Author NL was supported as a Frost Research Fellow in the Frost Summer 2016 Undergraduate Research Program. 


\section{$8 \quad$ References}

[1] B. Lucas and J. Hanson, "Thinking Like an Engineer: Using Engineering Habits of Mind and Signature Pedagogies to Redesign Engineering Education," Int. J. Eng. Pedagog., vol. 6, no. 2 , pp. 4-13, May 2016. https://doi.org/10.3991/ijep.v6i2.5366

[2] D. M. Riley, "Mindsets in Engineering," in Engineering and Social Justice, Morgan \& Claypool, 2008, pp. 33-47.

[3] B. L. Yoder, "Engineering by the numbers," 2017.

[4] S. K. A. Pfatteicher, "Death by design: Ethics, responsibility, and failure in the American civil engineering community, 1852-1986.," University of Wisconsin-Madison, 1996.

[5] E. T. Layton, "The Revolt of the Engineers: Social Responsibility and the American Engineering Profession," Revolt Eng. Soc. Responsib. Am. Eng. Prof., vol. 5, no. Sept 25, pp. 25-78, 1971.

[6] L. Mathis, Designed for use : usable interfaces for applications and the web. Pragmatic Bookshelf, 2011.

[7] M. Ritter and C. Winterbottom, UX for the Web: Build websites for user experience and usability, 1st ed. Packt Publishing, 2017.

[8] T. Litzinger, L. R. Lattuca, R. Hadgraft, and W. Newstetter, "Engineering Education and the Development of Expertise," J. Eng. Educ., vol. 100, no. 1, pp. 123-150, Jan. 2011.https://doi.org/10.1002/j.2168-9830.2011.tb00006.x

[9] D. Spencer, Card sorting : designing usable categories. Rosenfeld Media, 2009.

[10] M. T. H. Chi, P. J. Feltovich, and R. Glaser, "Categorization and representation of physics problems by experts and novices," Cogn. Sci., vol. 5, no. 2, pp. 121-152, Apr. 1981.https://doi.org/10.1207/s15516709 $\operatorname{cog} 0502$ 2 2

[11] H. R. Bernard, Research Methods in Anthropology - Qualitative and Quantitative Approaches. Altamira Press, 2002.

[12] S. A. Bissonnette et al., "Using the biology card sorting task to measure changes in conceptual expertise during postsecondary biology education," CBE Life Sci. Educ., vol. 16, no. 1, pp. 115, 2017. https://doi.org/10.1187/cbe.16-09-0273

[13] J. I. Smith et al., "Development of the biology card sorting task to measure conceptual expertise in biology," CBE Life Sci. Educ., vol. 12, no. 4, pp. 628-644, 2013. https://doi.org/10. 1187/cbe.13-05-0096

[14] F. E. Krieter, R. W. Julius, K. D. Tanner, S. D. Bush, and G. E. Scott, “Thinking Like a Chemist: Development of a Chemistry Card-Sorting Task to Probe Conceptual Expertise - Supporting Information," J. Chem. Educ., vol. 93, no. 5, pp. 811-820, 2016.

[15] K. R. Galloway, M. W. Leung, and A. B. Flynn, "A Comparison of How Undergraduates, Graduate Students, and Professors Organize Organic Chemistry Reactions," J. Chem. Educ., vol. 95, no. 3, pp. 355-365, Mar. 2018. https://doi.org/10.1021/acs.jchemed.7b00743

[16] "Roistr's automated card sort tool for information architecture and sitemaps." [Online]. Available: http://www.roistr.com/. [Accessed: 12-Jun-2018].

[17] "Online Card Sorting by Proven by Users." [Online]. Available: https://provenbyusers.com. [Accessed: 06-Dec-2018].

[18] J. vom Brocke, A. Simons, B. Niehaves, K. Riemer, R. Plattfaut, and A. Cleven, "Reconstructing the giant: On the importance of rigour in documenting the literature search process," in ECIS 2009 Proceedings, 2009, p. 161.

[19] Bransford, A. Brown, and R. Cocking, "How people learn: Mind, brain, experience, and school," Washington, DC Natl. Res. Counc., 1999.

[20] C. Zhou, "Learning Engineering Knowledge and Creativity by Solving Projects," Int. J. Eng. Pedagog., vol. 2, no. 1, pp. 26-31, Jan. 2012. https://doi.org/10.3991/ijep.v2i1.1873 
[21] S. A. Ambrose, M. Lovett, M. W. Bridges, M. DiPietro, and M. K. Norman, How learning works : seven research-based principles for smart teaching. 2010.

[22] M. Borrego, C. B. Newswander, L. D. Mcnair, S. Mcginnis, and M. C. Paretti, "Using Concept Maps to Assess Interdisciplinary Integration of Green Engineering Knowledge," 2009.

[23] I. Joao and J. Silva, "Concept Mapping and Mind Mapping to Lift the Thinking Skills of Chemical Engineering Students," Int. J. Eng. Pedagog., vol. 4, no. 5, pp. 42-48, 2019.https://doi.org/10.3991/ijep.v4i5.3538

[24] "List of concept- and mind-mapping software," Wikipedia. [Online]. Available: https://en.wikipedia.org/wiki/List_of_concept-_and_mind-mapping_software. [Accessed: 06Jun-2018].

[25] R. A. Streveler, T. A. Litzinger, R. L. Miller, and P. S. Steif, "Learning Conceptual Knowledge in the Engineering Sciences: Overview and Future Research Directions," 2008.https://doi.org/10.1002/j.2168-9830.2008.tb00979.x

[26] K. Pretz, "Does Having a License Make You an Engineer? - IEEE - The Institute," IEEE The Institute, 2017. [Online]. Available: http://theinstitute.ieee.org/ieee-roundup/blogs/blog/doeshaving-a-license-make-you-an-engineer. [Accessed: 14-Nov-2018].

[27] M. Jarlstrom, "Mats Järlström: I Am an Engineer," IEEE The Institute, 2017. [Online]. Available: http://theinstitute.iee.org/ieee-roundup/blogs/blog/mats-jrlstrm-i-am-an-engineer. [Accessed: 14-Nov-2018].

[28] E. Godfrey and L. Parker, "Mapping the cultural landscape in engineering education," J. Eng. Educ., vol. 99, no. 1, pp. 5-22, 2010. https://doi.org/10.1002/j.2168-9830.2010.tb01038.x

[29] A. L. Pawley, "Universalized Narratives: Patterns in How Faculty Members Define 'Engineering,"” J. Eng. Educ., vol. 98, no. 4, pp. 309-319, Oct. 2009. https://doi.org/10.1002/j.21689830.2009.tb01029.x

[30] B. M. Capobianco, H. A. Diefes-dux, I. Mena, and J. Weller, "What is an Engineer? Implications of Elementary School Student Conceptions for Engineering Education," J. Eng. Educ., vol. 100, no. 2, pp. 304-328, Apr. 2011.https://doi.org/10.1002/j.2168-9830.2011.tb00015.x

[31] M. Knight and C. Cunningham, "Draw an Engineer Test (DAET): Development of a Tool to Investigate Students' Ideas about Engineers and Engineering," Proc. 2004 Am. Soc. Eng. Educ. Аnnu. Conf., p. 11, 2004.

[32] E. Oware, B. Capobianco, and H. Diefes-Dux, "Gifted Students' Perceptions of Engineers ? A Study of Students In A Summer Outreach Program," in 2007 Annual Conference \& Exposition, 2007, pp. 12.784.1-12.784.13.

[33] B. Fralick, J. Kearn, S. Thompson, and J. Lyons, "How Middle Schoolers Draw Engineers and Scientists,” J. Sci. Educ. Technol., vol. 18, no. 1, pp. 60-73, 2009. https://doi.org/10.1007/ s10956-008-9133-3

[34] S. Thompson and J. Lyons, "Investigating the Long-Term Impact Of An Engineering Based Gk 12 Program On Students' Perceptions Of Engineering," in 2006 Annual Conference \& Exposition, 2006, pp. 11.846.1-11.846.15.

[35] M. Dyehouse, N. Weber, O. Kharchenko, D. Duncan, J. Strobel, and H. Diefes-Dux, "Measuring Pupil's Perceptions of Engineers: Validation of the Draw-an-Engineer (DAET) Coding System with Interview Triangulation," in Proceedings of the Research in Engineering Education Symposium 2011, 2011.

[36] T. Ganesh et al., "Eliciting Underserved Middle School Youths' Notions of Engineers: Draw an Engineer," in 2009 Annual Conference \& Exposition, 2009, pp. 14.525.1-14.525.14. https://doi.org/10.2190/WR.14.4.h

[37] C. Cunningham, M. Knight, W. Carlsen, and G. Kelly, "Integrating Engineering in Middle and High School Classrooms,” Int. J. Eng. Educ., vol. 23, no. 1, pp. 3-8, 2007. 
[38] A. Fryrear, "What's a Good Survey Response Rate?" 2015. [Online]. Available: https://www.surveygizmo.com/resources/blog/survey-response-rates/. [Accessed: 19-Nov2018].

[39] D. D. Nulty, "The adequacy of response rates to online and paper surveys: what can be done?" Assess. Eval. High. Educ., vol. 33, no. 3, pp. 301-314, 2008. https://doi.org/10.1080/ $\underline{02602930701293231}$

[40] K. D. Tanner, D. A. Chen, and G. D. Hoople, "Help with card sort data." Personal Communication, 2017.

\section{Authors}

Diana A. Chen is an Assistant Professor in Integrated Engineering at University of San Diego (5998 Alcala Park, San Diego, CA 92110). In collaboration with Hoople and colleagues, Chen is designing a new engineering curriculum to educate changemakers who understand that engineering is an inherently socio-technical activity. Chen received her MS and $\mathrm{PhD}$ in Civil Engineering from Clemson University, and a BS in Engineering from Harvey Mudd College. Her scholarly interests include social justice in engineering education and sustainability in the built environment. Email: (dianachen@sandiego.edu)

Gordon D. Hoople is an Assistant Professor in Integrated Engineering in the Shiley-Marcos School of Engineering at the University of San Diego (5998 Alcala Park, San Diego, CA 92110). Hoople, Chen, and colleagues are working to deconstruct the classic engineering division of social and technical. He earned his $\mathrm{MS}$ and $\mathrm{PhD}$ in Mechanical Engineering from University of California, Berkeley and a BS in Engineering from Harvey Mudd College. His research interests lie in engineering education, microfluidics, rapid prototyping, and STEAM. Before a career in academia, he worked as a structural dynamics consultant testing drones, aircraft, rockets, and roller coasters. Email: (ghoople@sandiego.edu)

Nico Ledwith earned his BS in Computer Engineering from California Polytechnic State University in in San Luis Obispo, California Spring 2017. He was the lead developer responsible for constructing the CARDS web interface. Ledwith now works as a junior application developer at Jabico Enterprises.

Eric Burlingame is a recent graduate of California Polytechnic State University in San Luis Obispo, California. He worked on the original implementation of the CardSort web application during his studies as an undergraduate at the university. He received his BS in Computer Science in Spring 2018 and will be working as a software engineer for Garmin in Salem, OR.

Seth D. Bush is the Chair of the Department of Chemistry and Biochemistry at California Polytechnic State University in San Luis Obispo California (1 Grand Ave, San Luis Obispo, CA 93407). He received his PhD in Physical Chemistry from the University of California, Berkeley and his bachelor's degree in Chemistry from Reed College. He is a Science Faculty with an Education Specialty whose research focuses on improving K-16 STEM education and studying Undergraduate Science Education reforms. Email: (sbush@,calpoly.edu) 
Gregory E. Scott is an Associate Professor in the Department of Chemistry and Biochemistry at the California Polytechnic State University in San Luis Obispo, CA (1 Grand Ave, San Luis Obispo, CA 93407). He holds a Ph.D. in physical chemistry from the University of Illinois and a B.S. in chemistry from Davidson College. His research includes studies in materials characterization and in education. Email: (gscott02@calpoly.edu)

Article submitted 2019-07-19. Resubmitted 2019-10-30. Final acceptance 2019-10-31. Final version published as submitted by the authors. 